\title{
Plantas medicinais comercializadas na feira livre do município de Patos, Paraíba
}

\section{Survey of medicinal plants sold at the free trade fair of the municipality of Patos, Paraíba, Brazil}

\author{
Felipe Silva de Medeiros ${ }^{1}$; Gabriela Braga de Sá2 ; Maysa Kevia Linhares Dantas ${ }^{3}$; Maria das Graças \\ Veloso Marinho de Almeida ${ }^{4}$
}

${ }^{1}$ Mestre em Ciências Florestais, Universidade Federal de Campina Grande, Centro de Saúde e Tecnologia Rural, Patos, Paraíba, Brasil, ;(83) 996092969, fsmedeiros.eng@gmail.com; ${ }^{2}$ Mestra em Ciências Florestais, Universidade Federal de Campina Grande, Centro de Saúde e Tecnologia Rural, Patos, Paraíba, (83) 999335256, gabrielasa.1 @ hotmail.com; ${ }^{3}$ Mestra em Ciências Florestais, Universidade Federal de Campina Grande, Centro de Saúde e Tecnologia Rural, Patos, Paraíba, (83) 996599731, maysakevia@ hotmail.com; ${ }^{4}$ Professora Doutora da Universidade Federal de Campina Grande, Centro de Saúde e Tecnologia Rural, Patos, Paraíba; (83) 988069352, mgvmarinho@bol.com.br.

\section{N O T A}

Recebido: 06/04/2018

Aprovado: 21/11/2018

\section{Palavras-chave:}

Estudos etnobotânicos

Raizeiros

Mercado municipal

Key words:

Ethnobotanical studies

Raizeiros

Municipal market

\section{R E S U M O}

Nas regiões mais pobres e até mesmo nas grandes cidades brasileiras, as plantas medicinais são comercializadas em feiras livres e mercados populares e também podendo ser encontradas em quintais residenciais e dentro das matas próximas as casas. Frente ao exposto, objetivou-se realizar um levantamento etnobotânico na feira livre e mercado municipal de Patos, Paraíba. A pesquisa ocorreu durante o mês de julho de 2017, por meio de visitas as feiras livres e entrevistas utilizando questionários do tipo semiestruturados aplicados aos comerciantes de plantas medicinais. Foram entrevistados ao total 9 raizeiros. Observou-se um total de 36 plantas medicinais comercializadas. As plantas mais citadas foram cajueiro e aroeira ambas com $(13,89 \%)$ e barbatimão $(11,77 \%)$. Os raizeiros e erveiros possuem uma grande importância social e econômica nas cidades, devido a maior facilidade de acesso ao tratamento de doenças. como também é fonte de renda desses comerciantes. Verificou-se que os raizeiros e erveiros que atuam no Mercado Central de Patos, possuem uma riqueza de conhecimentos sobre plantas medicinais e seus usos como também foi encontrada uma diversidade de espécies comercializadas.

\section{A B S T R A C T}

\begin{abstract}
In poorer regions and even in large Brazilian cities, medicinal plants are marketed in open markets and popular markets and can also be found in residential backyards and in the nearby woods the houses Ethnobotanical studies in open markets and markets are important, since many times the plants marketed are not studied or have not had their active principles identified to validate them as a medicine or to take advantage of them properly and economically. In view of the above, the purpose of this work was to conduct an ethnobotanical survey in the free market and municipal market of Patos, Paraiba, Brazil. The research took place during the month of July 2017, through visits to the free fairs and interviews using questionnaires of the semi-structured type applied to the traders of medicinal plants. A total of 9 raizers were interviewed. A total of 36 medicinal plants were marketed. The most cited plants were cashew and aroeira both with $(13.89 \%)$ and barbatimão (11.77\%). The raizeiros and herbs have great social and economic importance in the cities, because the use of medicinal species minimizes costs with pharmaceutical drugs, but also is a source of income for these merchants. There is a wealth of knowledge about the rootstocks and grasses that operate in the Central Market of Patos, as well as a diversity of species traded.
\end{abstract}

\section{INTRODUÇÃO}

O termo etnobotânica foi denominado pela primeira vez para designar o estudo sobre a utilização dos vegetais por aborígenes, que observou maneiras pelas quais poderia ser últil à investigação científica (ALBUQUERQUE, 2005; AMOROZO, 1996).

\section{Revista Verde}

ISSN 1981-8203

Pombal, Paraíba, Brasil
O conhecimento sobre plantas medicinais na maioria das vezes representa o único recurso terapêutico de muitas comunidades e grupos étnicos, que é disseminado de maneira informal por meio da medicina popular e transmitido de geração para geração por famílias, vizinhos e pessoas próximas sendo considerado tão antigo quanto à espécie 
humana. A área do conhecimento que utiliza plantas medicinais para cura das doenças é chamada fitoterapia e a ciência que estuda a relação (usos e costumes) dessas plantas com o homem é chamada de etnobotânica (ALBUQUERUE, 2005).

No Brasil, estudos etnobotânicos têm mostrado grande importância devido a descoberta de novas espécies da flora empregadas na medicina popular bem como seus princípios ativos, além de preservar o conhecimento tradicional (NETO et al., 2014). Além disso, a região Nordeste abriga em seu ecossistema, com predominância do Bioma Caatinga, uma grande diversidade de plantas medicinais e aromáticas com hábitos específicos, como por exemplo, a Carqueja (Baccharis trimera), a Aroeira (Myracroduon urundeuva) e o Mastruz (Chenopodium ambrosioides), que em sua maioria não são encontradas em outras regiões do mundo como o (Cumaru), Amburana cearenses (Arr. Cam.) A.C Smith.

A feira livre, desde suas origens, se constitui um território de compras, vendas e trocas de mercadorias diferenciadas (alimentos, vestimentas, animais, produtos típicos, etc.) que aglomera tradicionalmente, população de diversas classes sociais (SOUZA, et al, 2014). Esse tipo de comércio abrange diversas espécies e envolve, produtos e subprodutos e partes das plantas, no qual a maioria são identificadas apenas pelo nome popular.

Nesses ambientes de comercialização, se destacam os raizeiros e os erveiros. Os raizeiros são pessoas consagradas pela cultura popular no que diz respeito ao conhecimento sobre plantas medicinais, além da indicação, preparo e comercialização. Uma característica dos raizeiros é a venda de bebidas preparadas em forma líquida conhecida como "garrafadas", orientando como usá-las e prepará-las econômica e adequadamente (DOURADO et al., 2005; TRESVENZOL et al., 2006). Os erveiros são aquelas pessoas que apenas comercializam as plantas medicinais, indicando a recomendação terapêutica, forma de uso e a partes da planta que podem ser utilizada.

Embora algumas farmácias vendam medicamentos à base de plantas medicinais, à procura por estas plantas em feiras livres ainda é resistente. Conforme Veiga Junior e Pinto (2005), grande parte da comercialização de plantas medicinais é feita em farmácias e lojas de produtos naturais, onde preparações vegetais são comercializadas com rotulação industrializada e, em geral, essas preparações não possuem certificado de qualidade e são produzidas a partir de plantas cultivadas, o que descaracteriza a medicina tradicional que utiliza, quase sempre, plantas da flora nativa.

É necessário preservar o conhecimento popular sobre plantas medicinais, pois de certa forma, tem se restringido a um número cada vez menor de pessoas, e vem sofrendo sendo ameaçado pela medicina moderna e pelo desinteresse dos mais jovens das comunidades, interrompendo o processo de transmissão de saberes entre gerações.

Frente ao exposto, o objetivo com o presente trabalho foi realizar um levantamento etnobotânico na feira livre e mercado municipal de Patos - PB, listar as principais plantas comercializadas bem como caracterizar o perfil socioeconômico dos comerciantes desses recursos.

\section{MATERIAL E MÉTODOS}

A presente pesquisa foi desenvolvida no Mercado Central da cidade de Patos (Figura 2), localizada no estado da
Paraíba e distante $307 \mathrm{~km}$ da capital João Pessoa e que de acordo com dados do IBGE (2017) possui uma população estimada de 107.067 mil habitantes para o ano 2016. Possui clima do tipo Bsh-tropical, quente e seco. A cidade está inserida na microrregião de Patos, mesorregião do sertão paraibano e abrange uma área de $473,056 \mathrm{~km}^{2}$ de extensão e possui as coordenadas geográficas $7^{\circ} 01^{\prime} 46.25^{\prime \prime} \mathrm{S}$ 37²1644.09" W (IBGE, 2017).

Figura 1. Localização do município de Patos, no estado da Paraíba.

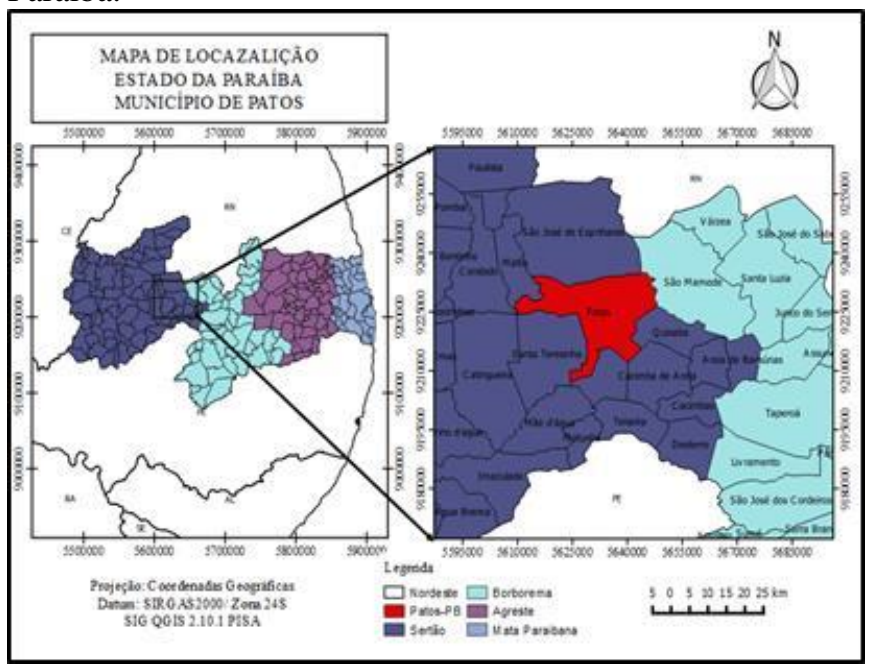

Fonte: IBGE (2017).

O Mercado Central está localizado na Rua Pedro Firmino e é considerado uma das construções mais peculiares da história de Patos, possuindo grande importância, pois atua de modo direto sobre os aspectos econômicos, sociais e culturais da cidade. O município possui também algumas feiras livres nas proximidades do mercado que comercializam plantas medicinais. De acordo com Anselmo (2012) as feiras realizadas no município localizam-se no referido Mercado municipal e acontecem todos os dias, são bastante diversificadas, apresentando gêneros alimentícios (frutas, verduras, legumes), vestuário e calçadista.

Figura 2. Mercado Público Municipal de Patos, Paraíba.

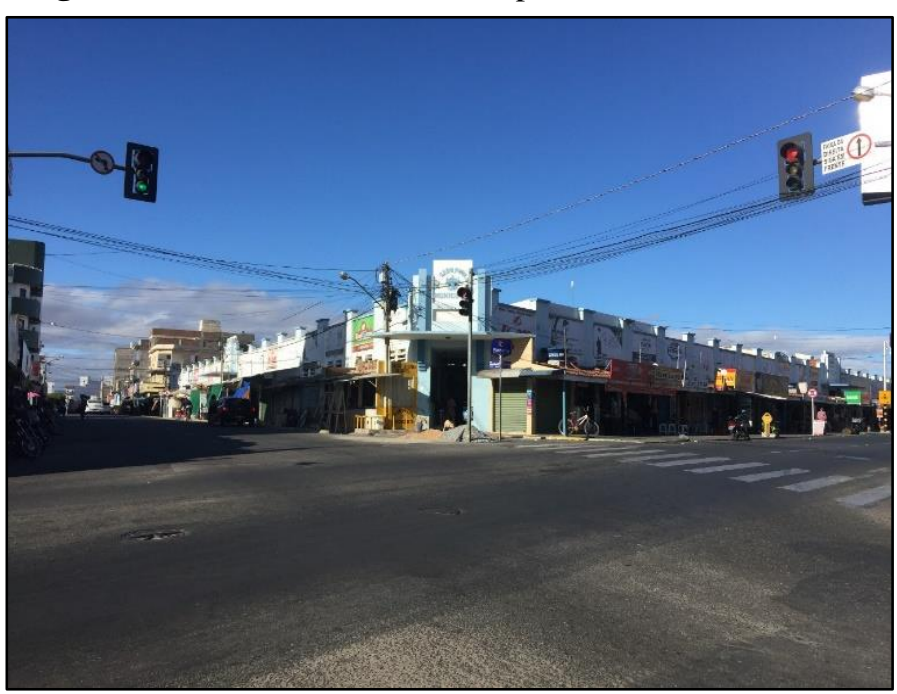

Fonte: Felipe Silva de Medeiros (2017)

A pesquisa foi realizada no mês de julho de 2017, por meio de visitas livres e entrevistas utilizando questionários do 
tipo semiestruturados aplicados aos comerciantes de plantas medicinais que atuam no mercado público e nas feiras livres presentes no município, buscando obter informações referentes às principais plantas comercializadas, bem como suas indicações terapêuticas, formas de preparo e partes dos vegetais mais usadas. A pesquisa foi realizada no período de julho a setembro de 2017. Primeiramente foram realizadas visitas para conhecer e explicar aos raizeiros o intuito da realização da pesquisa e para estabelecer o contato inicial com os raizeiros.

A coleta de dados foi realizada através da aplicação de questionários semiestruturados, abordando temas como: plantas medicinais reconhecidas para o tratamento de enfermidades e manutenção da saúde; formas de uso e partes da planta utilizadas; indicação terapêutica das plantas e locais de obtenção. As indicações terapêuticas foram agrupadas com base nos relatos dos informantes, preservando com maior ênfase a cultura local.

Para a seleção dos entrevistados, utilizou-se a técnica "bola de neve" (ou "Snow ball") (BAILEY, 1994), buscando aqueles moradores da comunidade que possuem amplo conhecimento acerca da utilização de plantas medicinais para, através destes, serem indicados outros moradores locais. Foram entrevistados 9 raizeiros.

Adicionalmente, também foram obtidas informações sobre o entrevistado, abordando aspectos socioeconômicos como renda, escolaridade e tempo de trabalho com comércio de plantas para fins medicinais.

\section{RESULTADOS E DISCUSSÃO}

Após a aplicação dos questionários, detectou-se que a maioria dos raizeiros é do sexo feminino, e podem ser enquadradas em uma faixa etária que varia de 30 a 40 anos. Em relação ao estado civil, observou-se que a maioria são pessoas casadas $(66,6 \%)$ e 33,4 \% dos raizeiros afirmaram ser solteiros.

Observou-se que a maioria dos entrevistados $(55,6 \%)$ reside no município de Patos de 10 a 30 anos, e os demais de 2 a 10 anos $(44,4 \%)$.

A distribuição dos entrevistados conforme nível de instrução indicou que a maioria $(66,7 \%)$ sabe ler e escrever, apenas um entrevistado afirmou saber ler e escrever pouco $(11,1 \%)$ e dois responderam que não sabem ler e nem escrever $(22,2 \%)$.

Sobre a quanto tempo comercializam plantas medicinais no Mercado Central os resultados elucidam que a maior parte dos comerciantes atuam a aproximadamente uma década. Mais precisamente, pode-se afirmar que $22,2 \%$ dos comerciantes atuam a pelo menos 2 anos, $22,2 \%$ atuam a pelo menos 8 anos e $55,6 \%$ possuem 10 anos ou mais de tempo de atuação no mercado, o que mostra uma experiência na atividade.

Para este tópico os resultados ilustram que $100 \%$ dos raizeiros e erveiros utilizam as plantas medicinais para consumo próprio indicando que eles além de venderem, acreditam no poder das plantas medicinais para curar as doenças. Em relação ao tempo de utilização dessas plantas a maioria $(33,4 \%)$ afirmou fazer uso dessas plantas como forma de remédios de 2 a 5 anos, o que pode estar relacionado com a "baixa" faixa etária identificada entre os comerciantes. Os demais afirmaram fazer uso em um período de 6 a 10 anos
$(22,2 \%), 11$ a $20 \operatorname{anos}(22,2 \%)$ e 21 a $30 \operatorname{anos}(11,1 \%)$ e mais de 30 anos $(11,1 \%)$.

Constatou-se também que $66,7 \%$ herdaram os conhecimentos sobre o uso das plantas medicinais dos pais e $11,1 \%$ dos avós, e ainda, dois entrevistados responderam ter adquirido esse conhecimento através de outras formas de veiculação do conhecimento $(22,2 \%)$, demonstrando que o ambiente familiar possui uma influência significativa na transmissão dos conhecimentos tradicionais. Rocha et al. (2013) em seu estudo realizado em Lagoa Nova - RN, registraram que em $80 \%$ dos casos a transmissão do conhecimento etnobotânico foi recebido através de familiares. Em um estudo similar realizado por Linhares et al. (2014) observou-se que a forma de aquisição dos conhecimentos sobre plantas medicinais se deu predominantemente por feirantes mais experientes representando $42 \%$.

A comercialização dessas plantas se dá nas mais variadas formas: cascas, raízes, sementes, entre outras. Quando questionados sobre a forma mais comercializada, pode-se afirmar que das partes geralmente mais utilizadas como medicinais nenhuma forma/parte da planta se sobressaiu em relação à outra, demonstrando que todas são úteis para fabricação de remédios. Desse modo, as partes mais vendidas foram cascas, folhas, folhas e raízes. Cascas e raízes, todas com $22,2 \%$ e cascas e folhas com $11,2 \%$. Em um estudo sobre as plantas medicinais comercializadas nas feiras de São Luís - MA, Linhares et al (2014) citaram que entre as partes vegetais usadas pelos feirantes, a folha foi a parte mais utilizada (37\%), seguindo-se da casca, com $23 \%$ das citações de uso.

As partes que não receberam nenhuma citação foram flores, sementes e frutos, conforme ilustrado na Figura 3. Martins e Costa (2016) em sua pesquisa em três municípios do Nordeste constataram que em relação ao emprego dessas partes para o preparo, a maior expressividade foi para a folha $(27,9 \%)$, seguida do caule $(27,3 \%)$.

Figura 3. Partes dos vegetais mais comercializadas no Mercado Público Municipal de Patos, Paraíba

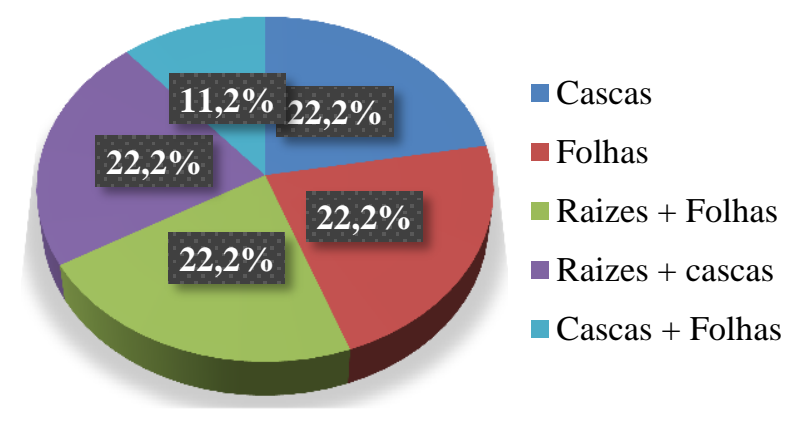

Quanto ao modo de preparo da planta para a sua utilização predominou-se a forma de chá e lambedor $(33,3 \%)$ e apenas chá $(22,2 \%)$, conforme observado na Figura 4. França et al. (2014) em uma pesquisa sobre as plantas medicinais comercializadas na feira livre no município de Pocinhos - PB, constataram que o chá $(92 \%)$ foi o modo de preparo mais citado entre os raizeiros. 
Figura 4. Formas de preparo das plantas comercializadas no Mercado Público Municipal de Patos, Paraíba

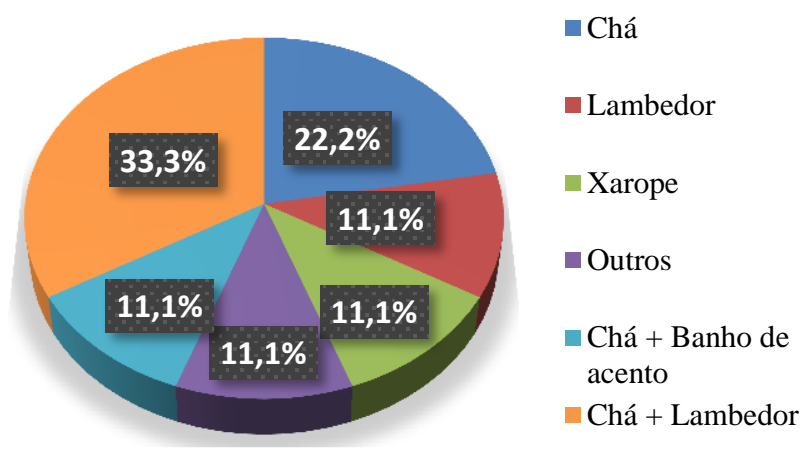

De acordo com os dados obtidos observa-se um total de 36 plantas medicinais comercializadas. $\mathrm{Na}$ tabela 01 são apresentadas estas espécies, bem como as indicações e as partes utilizadas. As plantas mais citadas foram cajueiro e aroeira ambas com $(13,89 \%)$ e barbatimão $(11,77 \%)$.

Observou-se que dores no estômago, gripes e inflamações são as indicações terapêuticas mais representativas dos entrevistados. Alves et al. (2007) no trabalho sobre as plantas medicinais comercializadas em Campina Grande (PB) destacaram que inflamações, diabetes e gastrites foram as enfermidades que tiveram o maior número de indicações.

Tabela 1. Plantas medicinais comercializadas no Mercado Público de Patos, Paraíba

\begin{tabular}{|c|c|c|c|c|c|c|}
\hline Nome popular & Família & Nome Científico & $\begin{array}{c}\mathrm{N}^{\mathrm{o}} \text { de } \\
\text { Citações }\end{array}$ & $\begin{array}{c}\% \text { de } \\
\text { Citações }\end{array}$ & $\begin{array}{l}\text { Parte da } \\
\text { planta } \\
\text { utilizada }\end{array}$ & Indicações \\
\hline Cajueiro & Anacardiaceae & Anacardium occidentale L. & 5 & 13,89 & Casca & Inflamações; \\
\hline Aroeira & Anacardiaceae & $\begin{array}{l}\text { Myracrodruon urundeuva } \\
\text { Allemão }\end{array}$ & 5 & 13,89 & Casca & $\begin{array}{l}\text { Inflamações; curar } \\
\text { Ferimentos; } \\
\text { úlceras }\end{array}$ \\
\hline Barbatimão & Fabaceae & $\begin{array}{l}\text { Pithecellobium cochliocarpum } \\
\text { (Gomez) Macbr }\end{array}$ & 4 & 11,11 & Raiz & $\begin{array}{l}\text { Inflamações; } \\
\text { higiene íntima } \\
\text { feminina; } \\
\text { policisto; } \\
\text { corrimento } \\
\text { feminino; }\end{array}$ \\
\hline Boldo & Monimiaceae & Peumus boldus Molina & 3 & 8,33 & Folha & $\begin{array}{l}\text { Calmante, dores } \\
\text { no estômago, } \\
\text { fígado; ressaca; } \\
\text { dores de barriga }\end{array}$ \\
\hline Erva doce & Apiaceae & Pimpinella anisum $\mathrm{L}$. & 3 & 8,33 & Folhas & $\begin{array}{l}\text { Calmante; cólicas; } \\
\text { dores estômago }\end{array}$ \\
\hline Endro & Apiaceae & Anethum graveolens $\mathrm{L}$. & 3 & 8,33 & Folhas & Dores de barriga \\
\hline Sene & Fabaceae & Cassia angustifólia Vahl & 2 & 5,56 & Folha & $\begin{array}{l}\text { Melhorar o } \\
\text { funcionamento do } \\
\text { intestino; sinusite }\end{array}$ \\
\hline $\begin{array}{l}\text { Alfazema } \\
\text { Brava }\end{array}$ & Lamiaceae & $\begin{array}{l}\text { Hyptis mutabilis var. bromfieldii } \\
\text { Briq. }\end{array}$ & 2 & 5,56 & Folha & $\begin{array}{l}\text { Gases no } \\
\text { intestino; }\end{array}$ \\
\hline Chanana & Passifloraceae & Turnera subulata $\mathrm{Sm}$. & 2 & 5,56 & Raiz & $\begin{array}{l}\text { Diabetes, "urina } \\
\text { solta" }\end{array}$ \\
\hline Quebra pedra & Euphorbiaceae & Phyllanthus niruri L. & 2 & 5,56 & $\begin{array}{l}\text { Raiz e } \\
\text { folhas }\end{array}$ & Cálculo renal \\
\hline Ameixa & Olacaceae & Ximenia americana $\mathrm{L}$. & 2 & 5,56 & Cascas & $\begin{array}{l}\text { Inflamações; } \\
\text { Regula o intestino }\end{array}$ \\
\hline Cumaru & Fabaceae & $\begin{array}{l}\text { Amburana cearensis (Allemão) } \\
\text { A.C. Sm. }\end{array}$ & 1 & 2,78 & Casca & Gripe \\
\hline Mororó & Fabaceae & $\begin{array}{l}\text { Bauhinia cheilantha (Bong.) } \\
\text { Steud. }\end{array}$ & 1 & 2,78 & Casca & Diabetes \\
\hline Jatobá & Fabaceae & $\begin{array}{l}\text { Hymenaea courbaril var. villosa } \\
\text { Y.T. Lee \& Andrade-Lima }\end{array}$ & 1 & 2,78 & Casca & Gripe; Anemia \\
\hline Canela & Lauraceae & Cinnamomum zeylanicum Blume & 1 & 2,78 & Folha & $\begin{array}{l}\text { Dores no } \\
\text { estômago }\end{array}$ \\
\hline Hibisco & Malvaceae & Hibiscus rosa-sinensis $\mathrm{L}$. & 1 & 2,78 & Folhas & Emagrecer \\
\hline Eucalipto & Myrtaceae & Eucalyptus globulus Labill. & 1 & 2,78 & Folhas & Febre \\
\hline Erva Cidreira & Verbenaceae & $\begin{array}{l}\text { Lippia alba (Mill.) N.E. Br. ex P. } \\
\text { Wilson }\end{array}$ & 1 & 2,78 & Folhas & Calmante \\
\hline Alecrim & Lamiaceae & Rosmarinus officinalis L. & 1 & 2,78 & Folhas & Gases \\
\hline Romã & Punicaceae & Punica granatum $\mathrm{L}$. & 1 & 2,78 & Semente & Tosse e gripe \\
\hline Gengibre & Zingiberaceae & Zingiber officinale Roscoe & 1 & 2,78 & Raiz & Tosse e gripe \\
\hline Arnica & Asteraceae & Solidago chilensis Meyen & 1 & 2,78 & Folhas & Dores no corpo \\
\hline $\begin{array}{l}\text { Umburana de } \\
\text { cambão }\end{array}$ & Burseraceae & $\begin{array}{l}\text { Commiphora leptophloeos (Mart.) } \\
\text { J.B.Gillett }\end{array}$ & 1 & 2,78 & Cascas & $\begin{array}{l}\text { Dor no estômago; } \\
\text { doenças } \\
\text { respiratórias. }\end{array}$ \\
\hline
\end{tabular}




\begin{tabular}{|c|c|c|c|c|c|c|}
\hline Copaíba & Fabaceae & Copaifera langsdorffii Desf. & 1 & 2,78 & Casca & $\begin{array}{l}\text { Dor muscular; } \\
\text { infecção }\end{array}$ \\
\hline $\begin{array}{l}\text { Canela de } \\
\text { velho }\end{array}$ & Melastomataceae & Miconia albicans (Sw.) Triana & 1 & 2,78 & Folha & Artrite \\
\hline Noni & Rubiaceae & Morinda citrifolia $\mathrm{L}$. & 1 & 2,78 & $\begin{array}{c}\text { Fruta/seme } \\
\text { nte }\end{array}$ & Câncer \\
\hline Unha de gato & Rubiaceae & $\begin{array}{l}\text { Uncaria tomentosa (Willd. ex } \\
\text { Roem. \& Schult.) DC. }\end{array}$ & 1 & 2,78 & Raiz & Cistos \\
\hline Uxi amarelo & Humiriaceae & Endopleura uchi (Huber) Cuatrec. & 1 & 2,78 & Casca & Cistos \\
\hline Assa peixe & Asteraceae & Vernonia schreb. & 1 & 2,78 & Folha & Tosse e gripe; \\
\hline Parreira brava & Menispermaceae & $\begin{array}{l}\text { Chondrodendron platiphyllum (A. } \\
\text { St.-Hil.) Miers }\end{array}$ & 1 & 2,78 & Raiz & $\begin{array}{l}\text { Doenças nos rins, } \\
\text { dores uterinas }\end{array}$ \\
\hline Urtiga branca & Losaceae & $\begin{array}{l}\text { Blumenbachia scabra (Miers) } \\
\text { Urb. }\end{array}$ & 1 & 2,78 & Folha & Inflamações; \\
\hline Quixabeira & Rutaceae & $\begin{array}{l}\text { Bumelia sartorum var. latifolia } \\
\text { Miq. }\end{array}$ & 1 & 2,78 & Cascas & $\begin{array}{l}\text { Ferimentos/Cicatri } \\
\text { zação }\end{array}$ \\
\hline Coco catolé & Palmae & Syagrus oleracea (Mart.) Becc. & 1 & 2,78 & Raiz & Infecção urinária; \\
\hline Sete sangrias & Boraginaceae & $\begin{array}{l}\text { Heliotropium nicotianaefolium } \\
\text { Poir. }\end{array}$ & 1 & 2,78 & Folha & $\begin{array}{l}\text { Bom para os rins; } \\
\text { pressão alta }\end{array}$ \\
\hline Marcela & Asteraceae & Egletes viscosa (L.) Less. & 1 & 2,78 & Flores & $\begin{array}{l}\text { Dores de } \\
\text { barriga/cólica }\end{array}$ \\
\hline Bágio Coronha & Fabaceae & Mucuna urens (L.) Medik. & 1 & 2,78 & Semente & Derrame, epilepsia \\
\hline
\end{tabular}

\section{CONCLUSÕES}

O uso de plantas medicinais é parte integrante da cultura nordestina, no Mercado Central de Patos, Paraíba existe diversidade de espécies comercializadas com grande riqueza de conhecimentos pelos raizeiros e erveiros.

As partes mais utilizadas sob a forma de chá são cascas e folhas. A importância das formas, parte e de onde utilizam essas plantas medicinais, como alternativas de tratamento de saúde, além de resgatar a cultura milenar que vem sendo transmitida de pais para filhos, é uma opção a mais para a população carente que tem grandes dificuldades no acesso a medicamentos farmacêuticos.

É necessária uma atenção maior para a necessidade de incentivos a pesquisa a fim de minimizar possíveis efeitos adversos provocados pelo consumo desses produtos.

\section{REFERÊNCIAS}

ALBUQUERQUE, U. P. Introdução à etnobotânica. 2 ed. Rio de Janeiro: Editora Interciência, 2005.

ALVES, R. R. N.; SILVA, A. A. G.; SOUTO, W. M. S.; BARBOZA, R. R. D. Utilização e Comércio de Plantas Medicinais em Campina Grande, PB, Brasil. Revista Eletrônica de Farmácia, v.4, n.2, p. 175-198, 2007.

AMOROZO, M. C. M. A abordagem etnobotânica na pesquisa de plantas medicinais. In: DISTASI, L. C. (Org.). Plantas medicinais: arte e ciência. São Paulo: UNESP. 1996, p. 47-68.

ANSELMO, A. F.; SILVA, C.G.; MARINHO, M.G.V.; ZANELLA, F.C.V.; XAVIER, D. A. Levantamento etnobotânico de plantas medicinais comercializadas por raizeiros em uma feira livre no município de Patos - PB. Revista de Biologia e Farmácia, Campina Grande, vol. especial, p. 39-48, 2012.

BAILEY, K. Methods of social research. 4.ed. New York: The Free Press, 588p, 1994.
DAVIS, E. W. Ethnobotany: an old pratice, a new discipline. In: Schultes, R. E. \& Reis, S. von (eds.). Ethnobotany evolution of a discipline. Discorides Press. p. 40-51. 1995.

DOURADO, E. R; DOCA, K. N. P.; ARAÚJO, T. C. C. Comercialização de plantas medicinais por "raizeiros" na cidade de Anápolis - GO. Revista Eletrônica de Farmácia, Suplemento, v. 2, p. 67-69, 2005.

FRANÇA, A. S.; FERNANDES, D. A.; MACÊDO, I. S. V.; OLIVEIRA, P. S.; COSTA, D. A. Plantas medicinais comercializadas na feira livre do município de Pocinhos-PB: conhecimentos dos raizeiros versus literatura. Scientia Plena, v.10, n.10, p. 1-9, 2014.

IBGE, Instituto Brasileiro de Geografia e Estatística. Divisão regional do Brasil em regiões geográficas imediatas e regiões geográficas intermediaras, Rio de Janeiro, 2017. Disponível em:

https://biblioteca.ibge.gov.br/visualizacao/livros/liv100600.pd f>. Acesso em 30/06/2018.

IBGE, Instituto Brasileiro de Geografia e Estatística, Cidades - Patos - PB. Disponível em: <https://cidades.ibge.gov.br/brasil/pb/patos/panorama>. Acesso em: 19 out 2018.

LIMA, E. P. R.; MAIA, M. S.; MATOS, W. R.. Levantamento das plantas medicinais comercializadas na feira livre do município de Duque de Caxias, Rio de Janeiro, Brasil. Revista Saúde \& Ambiente, Duque de Caxias-RJ, v.4, n.2, p.34-39, 2009.

LIMA, I. E. O.; NASCIMENTO, L. A. M.; SILVA, M. S. Comercialização de Plantas Medicinais no Município de Arapiraca - AL. Rev. Bras. Pl. Med., v. 18, n. 2, p. 462-472. Campinas, 2016.

LINHARES, J. F. P.; RODRIGUES, M.I.A.; HORTEGAL, E.V.; SILVA, P.S.S. Etnobotânica das principais plantas medicinais comercializadas em feiras e mercados de São 
Luís, Estado do Maranhão, Brasil. Revista Pan-Amaz Saude, v. 5, n. 3, p. 39-46, 2014.

MARTINS, E. S. S.; COSTA, J.C. Importância Relativa das Plantas Medicinais Comercializadas nas Feiras dos Municípios de Paulo Afonso - Bahia, Delmiro Gouveia Alagoas e Petrolândia - Pernambuco, Brasil. Opará: Etnicidades, Movimentos Sociais e Educação, v. 4, n. 5, p. 63-80, 2016.

NETO, F. R. G.; ALMEIDA, G. S. S. A.; JESUS, N. G.; FONSECA, M. R.. Estudo Etnobotânico de Plantas Medicinais Utilizadas pela Comunidade do Sisal no Município de Catu, Bahia, Brasil. Rev. Bras. Pl. Med., v. 16, n. 4, p. 856-865. Campinas, 2014.

ROCHA, F. A. G.; ARAÚJO, L. S. G.; LIMA, T. G. D.; SILVA， E. R.; SILVA， P. A.; GUNDIM， M. K. M.;
ARAÚJO, M. F. F.; COSTA, N. D. L. Características do Comércio Informal de Plantas Medicinais no Município de Lagoa Nova/RN. Holos, v. 5, p. 264-281, 2013.

SOUZA, D. H. B.; DANTAS, J. C.; MATIAS, T. H. B. O.; MOREIRA, E. Feira livre e cultura popular: espaço de resistência ou de subalternidade? VII Congresso dos geógrafos, 2014.

TRESVENZOL, L. M.; PAULA, J. R.; RICARDO, A. F.; FERREIRA, H. D.; ZATTA, D. T. Estudo sobre o comércio informal de plantas medicinais em Goiânia e cidades vizinhas. Revista Eletrônica de Farmácia, v.3, p. 22-28, 2006.

VEIGA JR, V. F.; PINTO, A. C. Plantas Medicinais: Cura Segura? Revista Química Nova, v. 28, n. 3, p. 519-528, 2005. 